Article

\title{
Experimental Study of Premixed Gasoline Surrogates Burning Velocities in a Spherical Combustion Bomb at Engine Like Conditions
}

\author{
Miriam Reyes* $*$, Francisco V. Tinaut and Alexandra Camaño \\ Department of Energy and Fluid-Mechanics Engineering, University of Valladolid, Paseo del Cauce, 59, \\ 47011 Valladolid, Spain; tinaut@eii.uva.es (F.V.T.); alexandra.lisbeth@gmail.com (A.C.) \\ * Correspondence: miriam.reyes@uva.es
}

Received: 10 June 2020; Accepted: 1 July 2020; Published: 3 July 2020

check for updates

\begin{abstract}
In this work are presented experimental values of the burning velocity of iso-octane/air, $\mathrm{n}$-heptane/air and n-heptane/toluene/air mixtures, gasoline surrogates valid over a range of pressures and temperatures similar to those obtained in internal combustion engines. The present work is based on a method to determine the burning velocities of liquid fuels in a spherical constant volume combustion bomb, in which the initial conditions of pressure, temperature and fuel/air equivalence ratios can be accurately established. A two-zone thermodynamic diagnostic model was used to analyze the combustion pressure trace and calculate thermodynamic variables that cannot be directly measured: the burning velocity and mass burning rate. This experimental facility has been used and validated before for the determination of the burning velocity of gaseous fuels and it is validated in this work for liquid fuels. The values obtained for the burning velocity are expressed as power laws of the pressure, temperature and equivalence ratio. Iso-octane, n-heptane and mixtures of $\mathrm{n}$-heptane/toluene have been used as surrogates, with toluene accounting for the aromatic part of the fuel. Initially, the method is validated for liquid fuels by determining the burning velocity of iso-octane and then comparing the results with those corresponding in the literature. Following, the burning velocity of n-heptane and a blend of $50 \%$ n-heptane and $50 \%$ toluene are determined. Results of the burning velocities of iso-octane have been obtained for pressures between 0.1 and $0.5 \mathrm{MPa}$ and temperatures between 360 and $450 \mathrm{~K}$, for n-heptane 0.1-1.2 MPa and 370-650 K, and for the mixture of $50 \%$ n-heptane $/ 50 \%$ toluene $0.2-1.0 \mathrm{MPa}$ and $360-700 \mathrm{~K}$. The power law correlations obtained with the results for the three different fuels show a positive dependence with the initial temperature and the equivalence ratio, and an inverse dependence with the initial pressure. Finally, the comparison of the burning velocity results of iso-octane and n-heptane with those obtained in the literature show a good agreement, validating the method used. Analytical expressions of burning velocity as power laws of pressure and unburned temperature are presented for each fuel and equivalence ratio.
\end{abstract}

Keywords: iso-octane; n-heptane; toluene; surrogate fuels; burning velocity; combustion bomb

\section{Introduction}

The laminar burning velocity is a fuel property of fundamental importance for predicting and studying the performance of internal combustion engines, which can be extremely useful in the analysis of fundamental processes and serve as a design utility during the engine design stage. The laminar burning velocity of premixed flames has been the focus of comprehensively experimental and numerical investigations. This property is essential in the analysis, design and implementation of internal combustion engines (ICE), because the burning velocity has a direct influence on the 
efficiency, emissions and burn rate in the combustion engine [1]. Burning velocities are implemented in combustion models to validate kinetic mechanisms. The laminar burning velocity of fuel mixtures can be obtained using several techniques, typically by combining experimental methods (pressure register, optical) with thermodynamic models and instabilities studies to consider the effects of flame stretch.

Precise measurements of values of the burning velocity are necessary to characterize fuels in premixed combustions and to validate combustion models [2]. A technique widely used in the literature, to present the results of the combustion rates of different fuels, is a correlation (power law) based on the initial conditions of the pressure, temperature and equivalence ratio of a given fuel mixture for a determined range of the pressure and temperature. These correlations provide very important information for evaluating the effect of fuels in spark ignition (SI) engines.

Due to the complexity of the gasoline composition and its variability, gasoline surrogates are used both experimentally and numerically to simplify calculations. Gasoline surrogates refers to fuels with a simpler representation of a fully mixed fuel, which can be primary reference fuels or binary mixtures based on the research octane number. Some of these gasoline surrogates are used as fuels for advanced combustion engines [3]. Surrogate fuels have a simpler composition which can facilitate simulations and evaluate the property effects and fuel-composition of the in-cylinder processes: vaporization, mixing and combustion, determining the processes in engine efficiency, emissions, performance, and requirements about the after-treatment systems [4]. Therefore, surrogate fuels have a great value as reference fuels which can be used to determine different parameters of interest in engine combustion without the effect of changes in the fuel-composition. The most common gasoline surrogates are iso-octane and n-heptane, the primary reference fuels (usually named PRF's) or binary mixtures of them for determining the research octane numbers (RON) in SI fuels.

Iso-octane and $\mathrm{n}$-heptane are standard gasoline surrogates for modeling combustion in SI engines because the processes of oxidation of $n$-heptane and iso-octane represent the ignition process and combustion characteristics of a gasoline fuel. For that reason, the effect of composition changes of multicomponent fuels can be simulated using binary mixtures of them as a first approximation [5].

Some investigations have been developed to determine the laminar burning velocity of iso-octane, n-heptane and binary mixtures of these two fuels, and, for that reason, iso-octane and n-heptane are used in this work to validate the methodology presented. Gülder [6], Bradley et al. [7], Metghalchi et al. [8], Galmiche et al. [9] and Müller et al. [10] obtained different correlations for the burning velocity of iso-octane as a function of pressure and temperature for diverse fuel/air equivalence ratios. Galmiche et al. [9] measured flame velocities in spherically expanding flames, from which the corresponding laminar burning velocities at a stretch rate of zero are derived. Iso-octane/air mixtures at initial temperatures between 323 and $473 \mathrm{~K}$, and pressures between 0.1 and $1.0 \mathrm{MPa}$ are studied over an extensive range of equivalence ratios, using a high-speed shadowgraph system. Varea et al. [11] used a high pressure and temperature combustion chamber to obtain the laminar burning velocity of iso-octane with a new method, from the difference between the flame speed and the intake gas velocity. They also obtained correlations as a function of pressure and temperature to express their effect. Marshal et al. [12] obtained the laminar burning velocity of iso-octane and n-heptane at elevated pressures and temperatures and they included combustion residuals in their experiments. They used a constant volume combustion vessel equipped with a Schlieren technique and obtained values for different ranges of pressure, temperature and equivalence ratios. The burning velocity of $n$-heptane has been obtained by different researchers: Davis and Law (1998, [13]) used a counterflow twin flame configuration, Huang et al. (2004, [14]) obtained the burning velocity of $n$-heptane and iso-octane (PRFs) in a counterflow configuration using a digital particle image velocimetry, Van Lipzig et al. (2011, [15]) investigated the adiabatic laminar burning velocity of $n$-heptane and iso-octane and their mixtures in a perforated plate burner, Sileghem et al. (2013, [16]) used the heat flux method to obtain the laminar burning velocities of iso-octane, n-heptane and toluene, Kwon et al. (2000, [17]) measured burning velocities in a spherical windowed chamber, Kumar et al. (2007, [18]) obtained the burning velocity of iso-octane and $n$-heptane with the counterflow flame technique (ambient pressure 
and different temperatures and equivalence ratios), Chong et al. (2011, [19]) obtained the burning velocity using the jet-wall stagnation flame configuration and the particle imaging velocimetry and Dirremberger et al. [20] used a perforated plate burner at 1 atm and $358 \mathrm{~K}$, for iso-octane, h-heptane and the toluene mixture.

In this work, the combustion process of iso-octane is studied and characterized in a constant volume combustion bomb with spherical geometry. After that, the burning velocities of $n$-heptane and a mixture of $n$-heptane and toluene are experimentally obtained at engine like conditions. This experimental facility has been used and validated before for the determination of the burning velocity of gaseous fuels and is validated in this work for liquid fuels. The values obtained for the burning velocity are expressed as power laws of the pressure, temperature and equivalence ratio. The experimentally registered pressure is the input for a two-zone thermodynamic model used to determine the burning velocity of different fuel mixtures.

This paper presents results of the burning velocities for gasoline surrogates at a high pressure and temperature, i.e., engine like conditions. In the literature there are not many results for gasoline surrogate fuels, and present results expand the burning velocity database to different conditions and mixtures including toluene for a surrogate fuel as a binary mixture with n-heptane. In addition, the burning velocity values are important for the studies developing explosion protection. Additionally, surrogate fuels are currently used as fuels in simulations for advanced combustion engines (for example HCCI, homogeneous charge compression ignition engines, or PCCI, premixed charge compression ignition engines), which means it is necessary to obtain results for the burning velocity of these fuels.

\section{Experimental Facility and Combustion Model}

The experimental installation used in this work consisted of a test facility designed for the characterization and investigation of the combustion process of gaseous and liquid fuels. The main part of the facility is a spherical constant volume combustion bomb (CVCB) with an acquisition system to register the parameters during the combustion and obtain information about the flame development, and supply lines for the introduction of fuels in the combustion bomb. Fuel evaporation is required for liquid fuels in order to obtain a homogeneous mixture at the beginning of the combustion process. In Figure 1, a scheme of the experimental facility can be seen, where the CVCB is a spherical space made of stainless-steel $200 \mathrm{~mm}$ in diameter, pressure and temperature transducers and two optical accesses which are radial and horizontal to detect and study the chemiluminescence emitted by the flame. The CVCB has been designed to withstand pressures up to $40 \mathrm{MPa}$ and temperatures up to $1073 \mathrm{~K}$ during the course of the combustion process. There are two electrodes inside the CVCB between which the spark is discharged to start the combustion at the geometrical center of the sphere, for more details see [21].

The initial conditions of pressure, temperature and fuel/air ratio were set up at the beginning of each combustion test. Liquid fuels were directly introduced in the combustion chamber and the air was added later with the corresponding line supply. A mixture time is necessary to get a homogeneous mixture inside the CVCB. Once the combustion was initiated, a spherical flame front propagates inside the combustion bomb compressing adiabatically and burning the fresh mixture. During the combustion process development, a piezoelectric transducer, Kistler 7063 type (maximum calibration error of $0.06 \%$ ), registered the evolution of the pressure. This transducer was connected to a KISTLER 5018A1000 charge amplifier (maximum calibration error of $0.3 \%$ ). The output signal of the charge amplifier was recorded on a Yokogawa DL750 Scopecorder (16 bits AD converter). The estimated error of the pressure acquisition is $0.36 \%$ over the measuring range. With the acquisition system it is possible to obtain values of up to $30,000 \mathrm{~Hz}$. Additional details of the experimental facility and of the use of $\mathrm{OH}$ and $\mathrm{CH}$ chemiluminescence for flame characterization can be seen in Tinaut et al. [22].

The burning velocity was determined by the two-zone combustion analysis model, in which the main input was the temporal evolution of the pressure registered during the combustion, in addition to the initial values of the fuel-composition and mass of the fuel blend. 


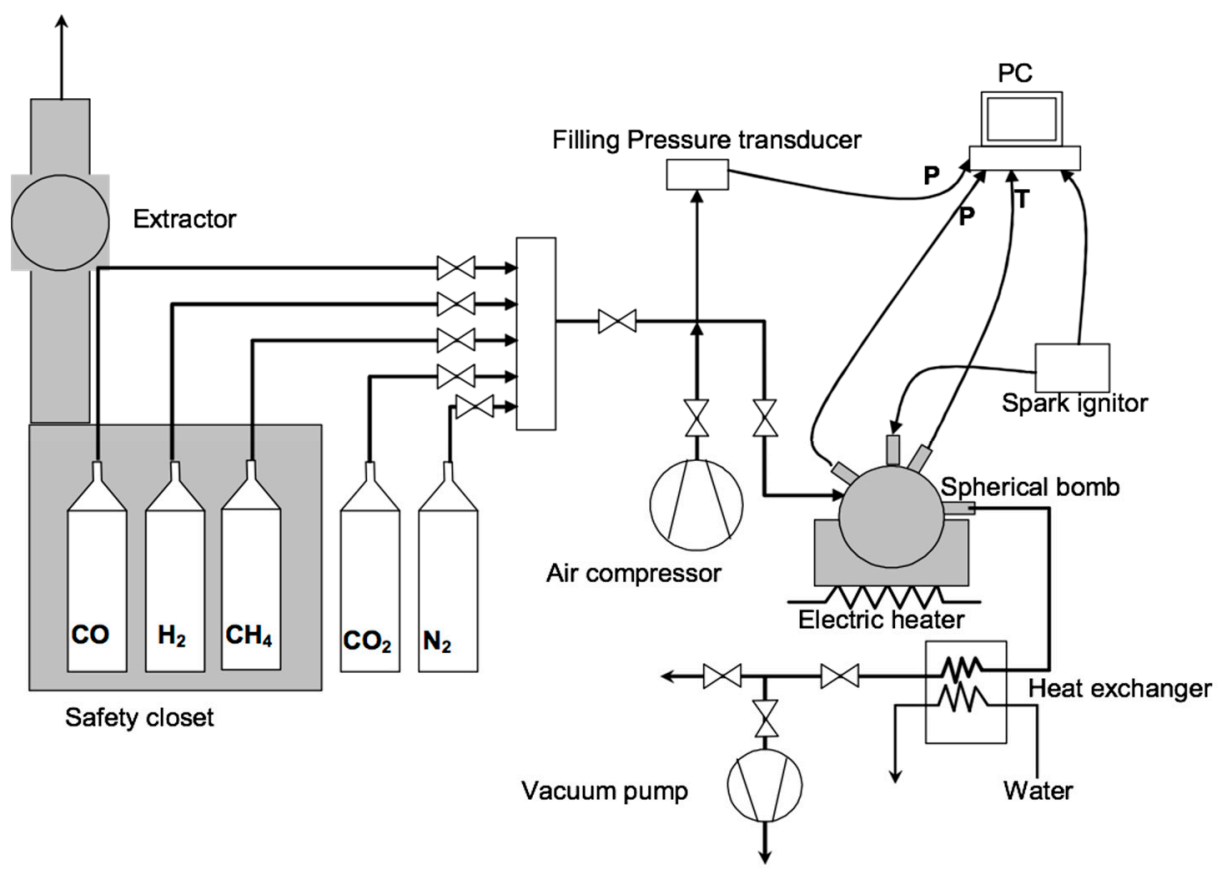

Figure 1. Experimental facility.

The thermodynamic combustion model considers the division of the combustion chamber in two different zones: the burned zone (designated with a b subscript) and unburned zone (designated with a ub subscript). In each zone, there were applied conservation and ideal gas equations [23-25]. Once the combustion has been initiated by the spark plug, a flame front appears and the spherical flame moves concentrically with the vessel walls, as the unburned or fresh mixture transforms into burned mixture. The outputs of this model are the temperatures of both zones, the burned mass fraction, the flame front surface and the burning velocity, among other variables [23]. The burning velocity, $\mathrm{C} c$, was determined from the mass burning rate $\left(\dot{m}_{b}\right)$, the flame front surface $\left(A_{f}\right)$ and from the unburned density $\left(\rho_{u b}\right)$ according to the next expression:

$$
C_{c}=\frac{\dot{m_{b}}}{\rho_{u b} A_{f}}
$$

As indicated in [26], some parts of the burning velocity plots were discarded to calculate the laminar burning velocity: some part of the initial points (due to the effects of the spark plug on the combustion onset, numerical oscillations and stretch rate) and some part of the final points (the autoignition processes and cellularity effects due to instabilities). A cellular combustion is obtained under certain conditions in which a cellular flame front ends in an apparent burning velocity higher than the laminar one when both velocities are referred to a smooth flame front-they can also be referred to the spherical one. The last part of the combustion process also had to be discarded because the flame front reached the CVCB wall and it could disturb the free flame development. The unburned temperature could also be locally perturbed due to heat transmission, and the hypothesis of adiabatic compression for the unburned gas temperature calculation will stop being fulfilled and some buoyancy effects may appear.

\section{Results}

Initially, the methodology for the determination of the burning velocity was presented and validated for liquid fuels. Iso-octane is the fuel used because of the existence of the extensive literature studying combustion. After that, the burning velocity of n-heptane and a mixture of $50 \% \mathrm{n}$-heptane $/ 50 \%$ 
toluene are obtained for different conditions of the pressure, temperature (engine like conditions) and equivalence ratio, and are compared with literature data.

\subsection{Validation of the Methodology for Liquid Fuels: Iso-Octane}

In this section, the methodology for the determination of the burning velocity of liquid fuels is validated using iso-octane as a fuel. This methodology has been previously validated with gaseous fuels.

The influence of pressure and temperature is studied in a stoichiometric mixture of iso-octane and air for the conditions shown in Figure 2, with an initial pressure between 0.1 and $0.5 \mathrm{MPa}$ and initial temperature between 360 and $450 \mathrm{~K}$. In Figure 3, the pressure evolution versus the flame front radius in a combustion process of stoichiometric iso-octane is plotted. In Figure 3, it is possible to see that the pressure reaches $50 \%$ of its maximum value when the flame front is close to the wall of the CVCB (94.2 mm radius). In Figure 4, the temporal evolution of the pressure (Figure 4a, experimental values) and burning velocity (Figure $4 \mathrm{~b}$, obtained by means of the $2-\mathrm{Z}$ model) is plotted versus unburned temperature, for stoichiometric combustions of iso-octane at different initial conditions. It can be seen in both Figures that the burning velocity reduces as the initial pressure is increased.

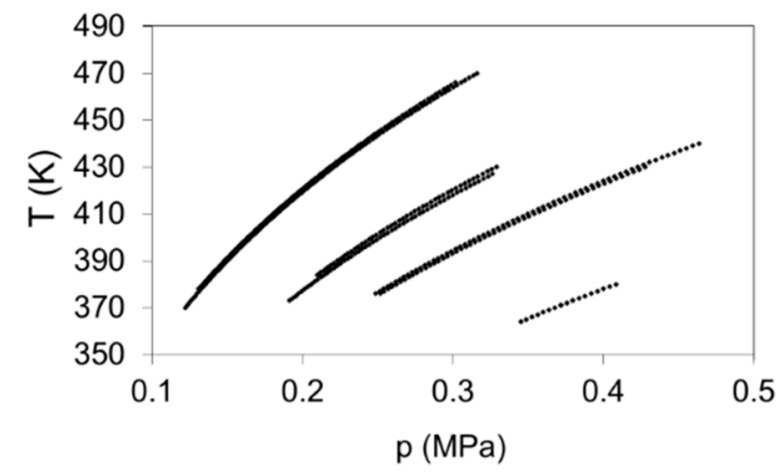

Figure 2. Pressure-temperature lines of adiabatic compression of iso-octane used for the calculation of the burning velocity for stoichiometric conditions.

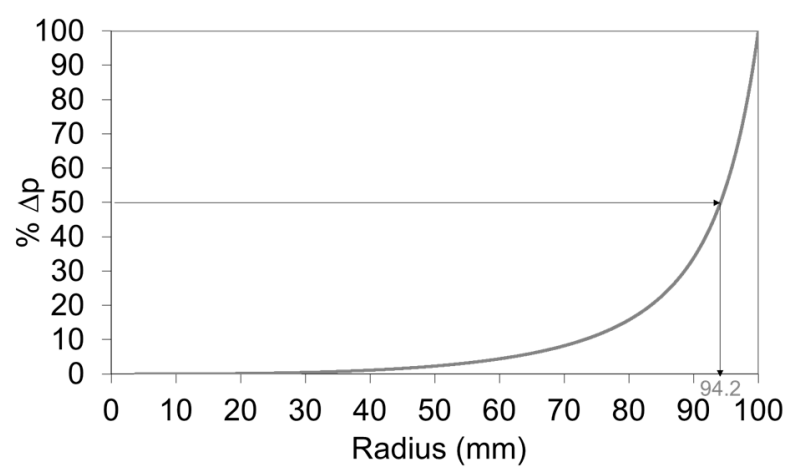

Figure 3. Pressure increase versus the flame front radius in a combustion of iso-octane, with a stoichiometric fuel/air equivalence ratio, $0.1 \mathrm{MPa}$ and $353 \mathrm{~K}$ initial conditions.

The range of valid data used for the burning velocity determination excludes initial data affected by the ignition process (a value of the mass fraction burned, equal to 0.05 , is used as the initial validity point for the burning velocity). It also excludes the final points and data affected by instabilities and the autoignition process. Burning velocities are obtained with the two-zones thermodynamic model. The burning velocity shows a smooth increment, except for the lower pressure combustion where it is possible to appreciate a bump in the curve, caused by the instabilities of the flame front. Additionally, autoignition phenomena may arise, generating oscillations in the pressure line and a characteristic sharp bump in the burning velocity plots (as can be seen in some experiments presented in following sections). 


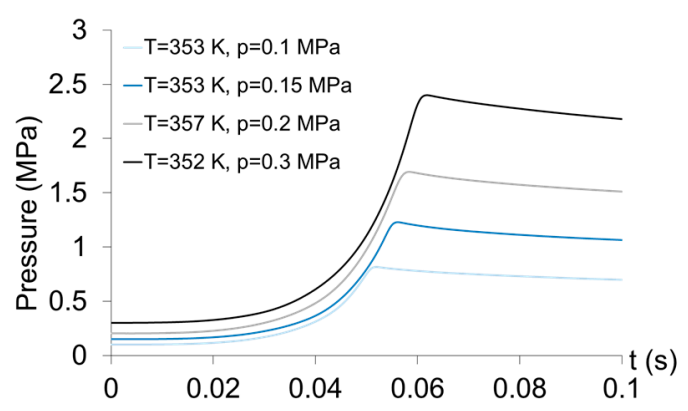

(a)

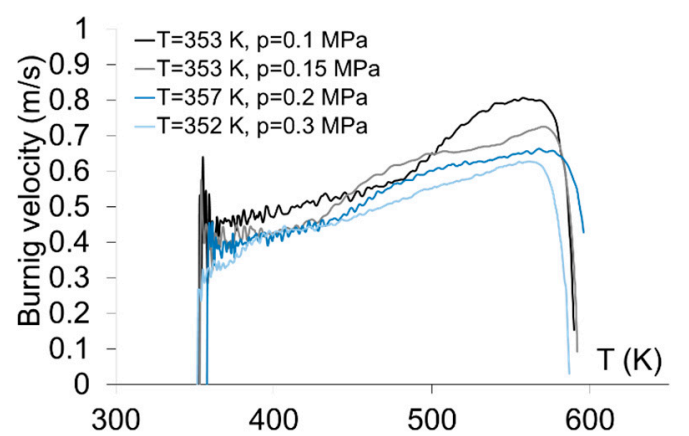

(b)

Figure 4. (a) Pressure; (b) burning velocity. The temporal evolution of the pressure and burning velocity of iso-octane versus the unburned temperature for stoichiometric mixtures with varying initial pressures.

The burning velocity values shown in Figure $4 \mathrm{~b}$ can be fitted to a power law correlation as a function of pressure and temperature, of the type proposed by Metghalchi-Keck [8], as seen in Equation (2), where $C_{c}$ is the burning velocity in $\mathrm{m} / \mathrm{s}, C_{c o}$ is the reference burning velocity at the $T_{o}$ and $p_{0}, \alpha$ and $\beta$ are the exponents of temperature and pressure to be determined. The value of the correlation coefficient $R^{2}$ is 0.96 and the standard error of estimation is $4 \%$.

$$
\begin{gathered}
C_{c}=C_{c o}\left(\frac{T}{T_{o}}\right)^{\alpha}\left(\frac{p}{p_{o}}\right)^{\beta}, \\
C_{c}(\text { iso-octane })=0.32\left(\frac{T}{300}\right)^{1.91}\left(\frac{p}{0.1}\right)^{-0.25},
\end{gathered}
$$

In Table 1 the correlation obtained in the present work is presented together with the expressions obtained by Gülder [9], Bradley et al. [7], Metghalchi et al. [10], Galmiche et al. [15] and Müller et al. [11] for the stoichiometric fuel/air equivalence ratio. In Müller's expression, $T_{0}$ is the temperature of the interior zone, which marks the transition between the reaction zone and the unburned zone (the temperature that limits chain brain and chain break reactions), $Y_{f}$ is the unburned fuel mass fraction and Tad is the adiabatic temperature.

Table 1. Correlations for the burning velocity of stoichiometric iso-octane.

\begin{tabular}{cc}
\hline Gülder [6] & $C_{c}=0.45\left(\frac{T}{300}\right)^{1.56}\left(\frac{p}{0.1}\right)^{-0.22}$ \\
\hline Metghalchi_Keck [8] & $C_{c}=0.25\left(\frac{T}{300}\right)^{2.18}\left(\frac{p}{0.1}\right)^{-0.16}$ \\
\hline Present work & $C_{c}=0.32\left(\frac{T}{300}\right)^{1.91}\left(\frac{p}{0.1}\right)^{-0.25}$ \\
\hline Bradley et al. [7] & $C_{c}=0.40\left(\frac{T}{300}\right)^{1.01}\left(\frac{p}{0.1}\right)^{-0.28}$ \\
\hline Galmiche et al. [9] & $C_{c}=0.56\left(\frac{T}{423}\right)^{1.89}\left(\frac{p}{0.1}\right)^{-0.26}$ \\
\hline Müller et al. [10] & $C_{c}=2.93 \times 10^{3}\left(\frac{p}{3.80 \times 10^{7}}\right)^{\left(1.22 \times 10^{-3}\right)} Y_{f}^{0.56}\left(\frac{T_{a d}-T^{o}}{T_{a d}-T}\right)^{2.52}\left(\frac{T}{T_{o}}\right)$ \\
\hline
\end{tabular}

In Figure $5 \mathrm{a}$, the burning velocity of the stoichiometric mixtures of iso-octane and air is plotted versus the unburned temperature for an initial pressure of 0.5 MPa. The line obtained in this work is placed at the center of the plot, with a slope similar to the one obtained by Müller et al., in spite of the fact that the Müller expression is different and they obtain it from a program with an extensive reaction mechanism. Galmiche et al. [9] measured the flame velocities of spherically expanding flames using a combustion chamber equipped with a high-speed shadowgraph system. The differences between the expression of Bradley et al. [7] and Metghalchi et al. [8] are due to the fact that they considered all 
the data obtained during the combustion processes without any distinction between the laminar and cellular zone, which explains the higher slope of the Metghalchi correlation. Gülder [6] obtained the expression for the burning velocity in a combustion bomb using ionization sensors in the combustion zone, leading to higher values.

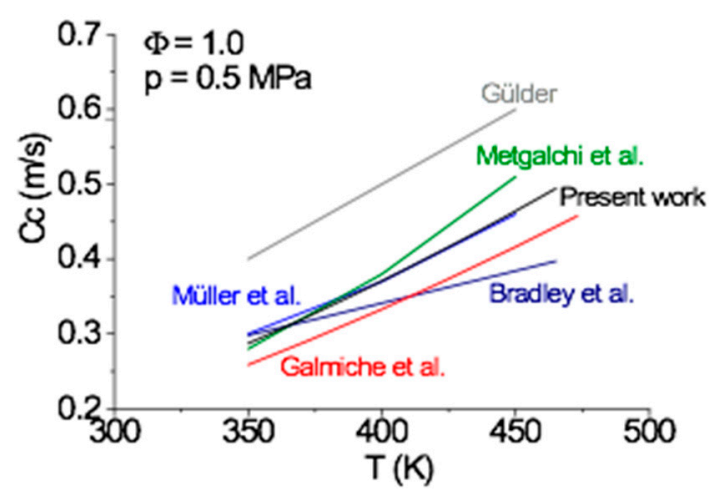

(a)

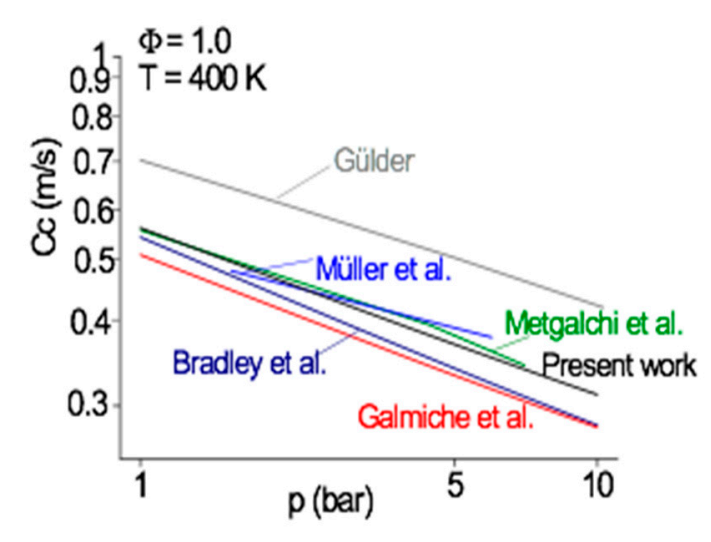

(b)

Figure 5. The burning velocity for stoichiometric iso-octane versus temperature (a) and pressure (b).

In Figure $4 b$, the burning velocity versus the pressure is represented for an initial temperature of $400 \mathrm{~K}$. The tendencies of the present work results are similar to those explained before: the slope is similar to the one obtained by Müller et al. [10]. The differences with the correlations obtained by Gülder [6] and Bradley et al. [7] are due to a different measurement method being used, while the differences with the Metghalchi and Keck [8] values are due to the range of considered data.

The stoichiometric iso-octane burning velocity is represented in Figure 6 versus the temperature and pressure, for the expressions shown in Table 1. The highest values of the burning velocity are obtained for elevated temperatures and low pressures, in all the cases. In Figure 6, all the correlations are represented together in order to compare them more clearly. In addition, some experiments with varying equivalence ratios were developed to compare with the literature data, as seen in Figure 7. The values obtained in the present work (black points) are compared with the values of Galmiche et al. (2012, [9]), Metghalchi and Keck (1982, [8]), Varea et al. (2013, [11]), Marshall et al. (2011, [12]) and Gülder (1982, [6]). It can be seen that the values obtained in the present work agree with the rest of the data.

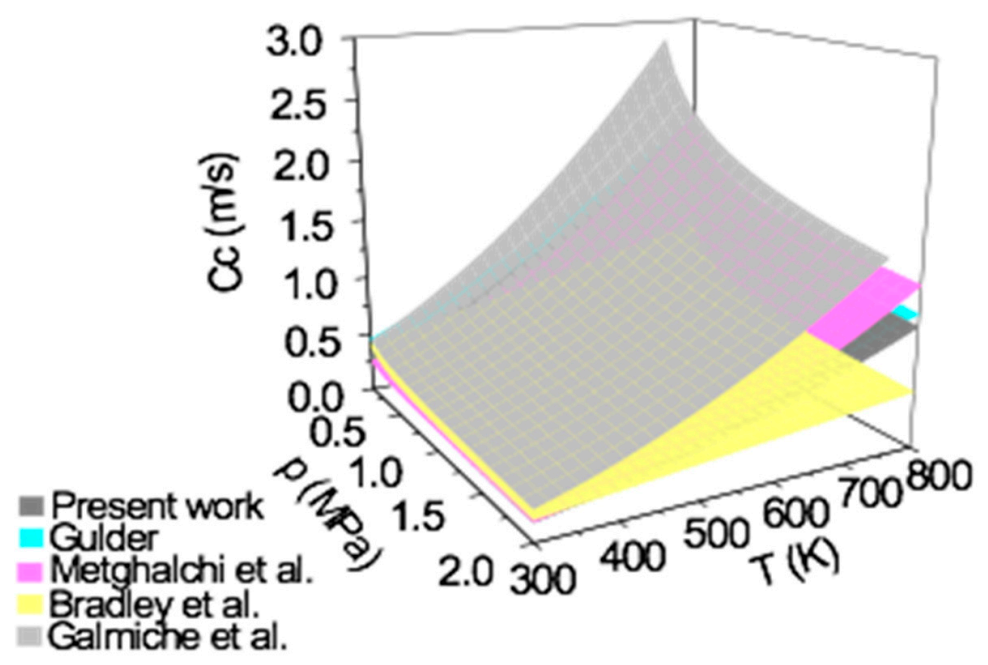

Figure 6. The burning velocity of iso-octane as a function of temperature and pressure for the stoichiometric equivalence ratio. Comparison between the expressions obtained by Gülder [6], Metghalchi and Keck [8], Bradley et al. [7], Galmiche et al. [9] and those obtained in the present work. 
As a conclusion of this section, it is possible to say that the methodology for the determination of the burning velocity of liquid fuels in the CVCB has been validated and the results obtained for other fuels will be presented in the following sections.

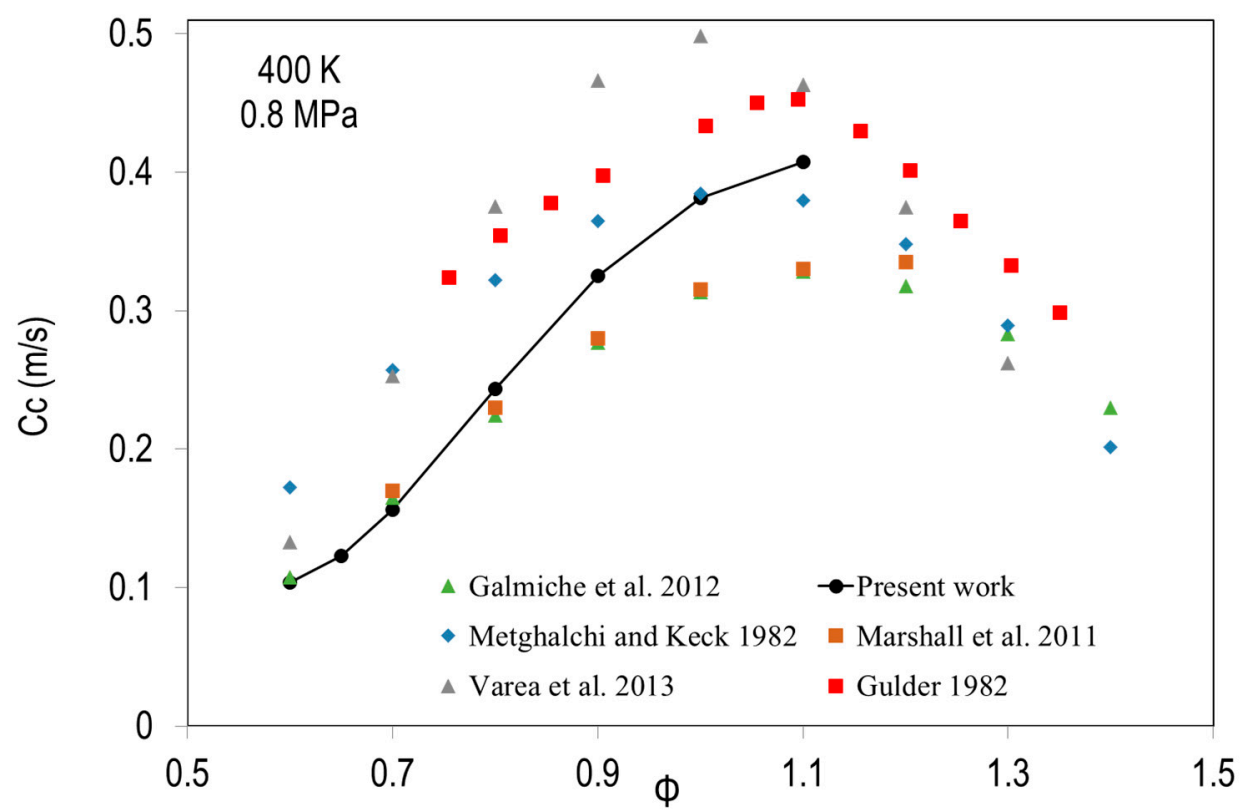

Figure 7. Comparison of the burning velocity of iso-octane versus the equivalence ratio, for $0.8 \mathrm{MPa}$ and $400 \mathrm{~K}$ of the initial conditions.

\subsection{Burning Velocity of n-Heptane}

In this section, the results for the burning velocity of n-heptane/air mixtures in the CVCB are presented for the different initial conditions of the pressure and temperature. The initial conditions are chosen to be able to reach the range of pressure and temperature obtained by the internal combustion in engines during the progress of the combustion, as can be seen in Figure 8a. The objective of these experiments is to characterize the burning velocity of n-heptane through correlations as a function of pressure and temperature and the fuel/air equivalence ratio, Equation (2).

\subsubsection{Results of n-Heptane for a Stoichiometric Mixture}

A pressure-temperature diagram of all the data used to determine the burning velocity of $\mathrm{n}$-heptane in stoichiometric conditions is shown in Figure 8a. In this figure, points represent the adiabatic evolution of the pressure and temperature during the combustion process inside the CVCB, starting from the initial conditions of pressure and temperature. Figure 8a delimits the validity range of the obtained correlation, with an initial pressure between 0.1 and $1.2 \mathrm{MPa}$ and initial temperature between 370 and $650 \mathrm{~K}$. 


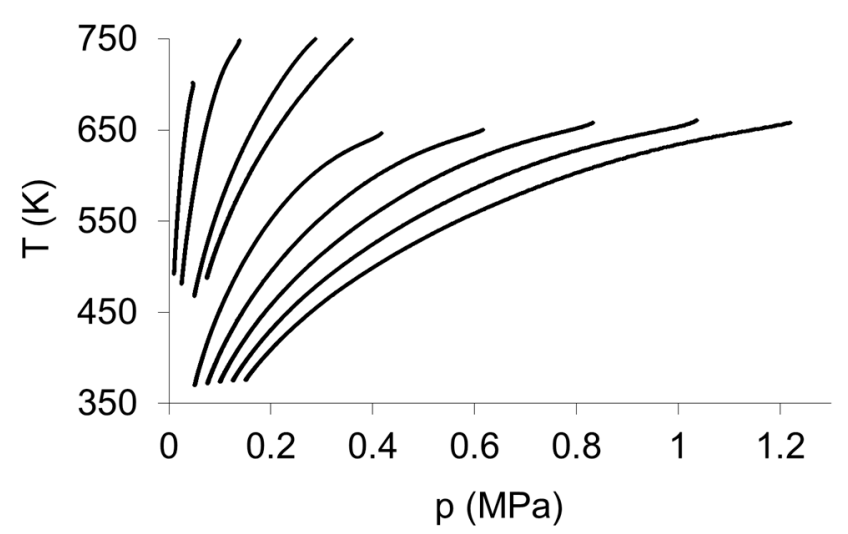

(a)

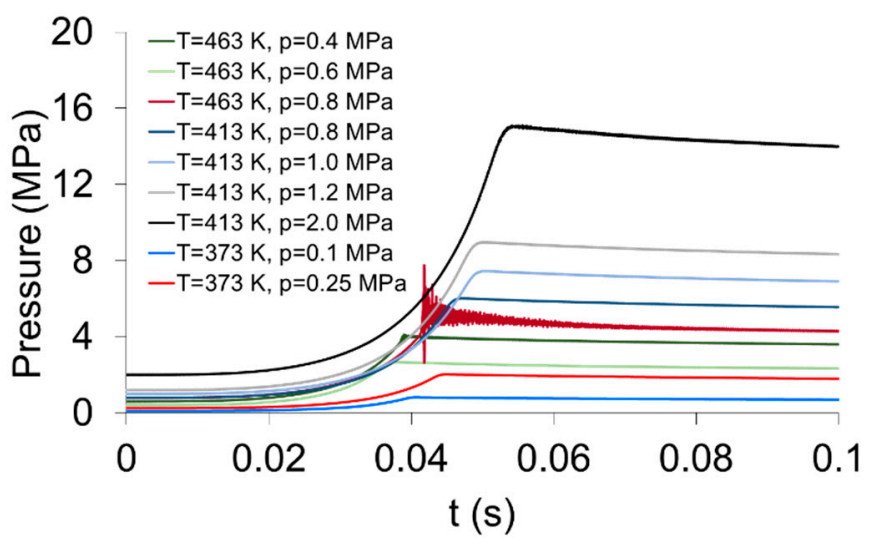

(b)

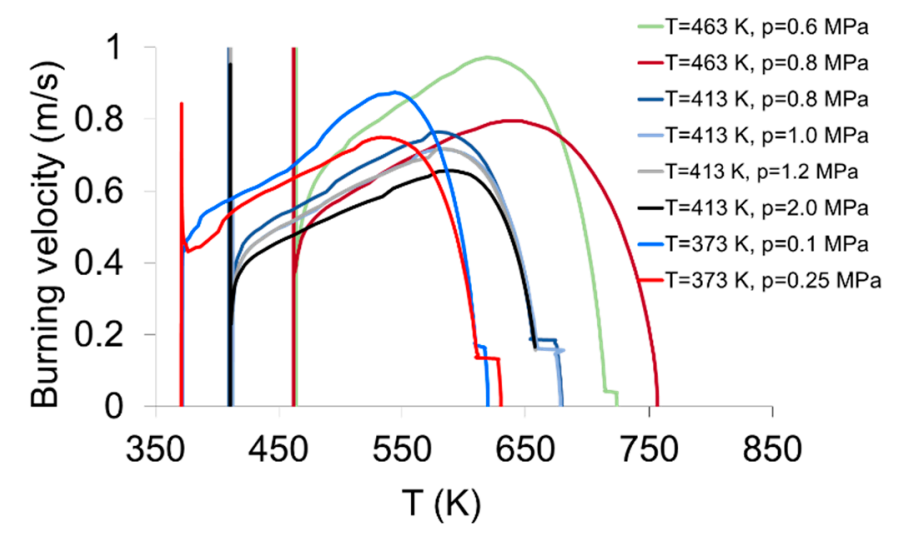

(c)

Figure 8. (a) Pressure-temperature diagram; (b) pressure; (c) burning velocity. The temporal evolution of the pressure and burning velocity of n-heptane versus the unburned temperature for stoichiometric combustions.

Once the mixture is ignited at the center of the combustion chamber, the temporal evolution of the pressure during the combustions for stoichiometric mixtures of n-heptane/air for different initial conditions are plotted in Figure $8 \mathrm{~b}$ (combustions are ordered by the initial temperature). Pressure starts growing until the flame front touches the CVCB wall, and the pressure curves reach their maximum 
value. As the initial pressure increases, for the same initial temperature, combustions are slower and the rise of the curve is smoother, and the final pressure increases too, due to the adiabatic compression inside the CVCB. For the combustion of $463 \mathrm{~K}$ and $0.8 \mathrm{MPa}$ (turquoise line), the autoignition of the n-heptane mixture is reached, causing vibrations in the pressure curve. Additionally, a low autoignition process is observed in the pressure curve for $463 \mathrm{~K}$ and $0.4 \mathrm{MPa}$ (dark blue line). Autoignition takes place inside the combustion bomb when the autoignition conditions are reached during the adiabatic compression, and a part of the unburned mixture autoignites. Burning velocities (obtained with the thermodynamic model) versus unburned are represented in Figure 8c, where it is possible to see that as the pressure increases, for a given temperature, the burning velocity decreases. In contrast, when the pressure is constant and the temperature increases, the burning velocity increases with temperature. Results obtained for n-heptane are qualitatively similar to the case of iso-octane.

A Metghalchi-Keck type correlation for the stoichiometric combustion of n-heptane is shown in Equation (4), where the value of the correlation coefficient $R^{2}$ is 0.989 and the standard error of estimation is $2 \%$.

$$
F r=1 \rightarrow C c\left(\frac{m}{s}\right)=0.35\left(\frac{T}{T_{0}}\right)^{2.21}\left(\frac{p}{p_{o}}\right)^{-0.21},
$$

\subsubsection{Results of $n$-Heptane for a 0.9 Fuel/Air Equivalence Ratio}

The validity ranges of the data used for the determination of the burning velocity correlation of n-heptane with a 0.9 equivalence ratio are shown in thick trace on the temperature-pressure evolution lines of Figure 9a, with an initial pressure between 0.1 and 1.2 $\mathrm{MPa}$ and an initial temperature between 360 and $650 \mathrm{~K}$. The temporal evolution of pressure in the combustions of $\mathrm{n}$-heptane are shown in Figure $9 b$, and the corresponding burning velocities are plotted in Figure 9c.

The general trend is that the burning velocity increases with the initial temperature, and decreases with the initial pressure. It can be seen that in some of the experimental cases, characterized by high initial temperatures and/or pressures (450 K-1.7 MPa-yellow line, $451 \mathrm{~K}-2.0 \mathrm{MPa}$-blue line, and $474 \mathrm{~K}-0.8 \mathrm{MPa}$-red line), appear some oscillations in the pressure curve due to autoignition process. The corresponding burning velocity plots show a significant increment in the apparent burning velocity.

The explanation of this behavior is the onset of autoignition processes, which lead to a more violent and faster combustion process than the previous laminar premixed combustion. This autoignition behavior did not appear in the case of iso-octane (in the tested experimental range), which agrees with the well-known difference between the octane number of iso-octane and n-heptane. When the autoignition takes place in the fresh mixture, the diagnostic model gives very high values of the apparent burning velocity, because during this process some autoignition reactions play an important role in the unburned zone with a flame front, which are not geometrically identified. This behavior does not appear when the equivalence ratio is stoichiometric.

The obtained correlation with the data represented in Figure $9 \mathrm{c}$ is the following, where the value of the correlation coefficient $\mathrm{R}^{2}$ is 0.973 and the standard error of estimation is $7 \%$.

$$
F r=0.9 \rightarrow C c\left(\frac{m}{s}\right)=0.33\left(\frac{T}{T_{0}}\right)^{2.73}\left(\frac{p}{p_{o}}\right)^{-0.30}
$$




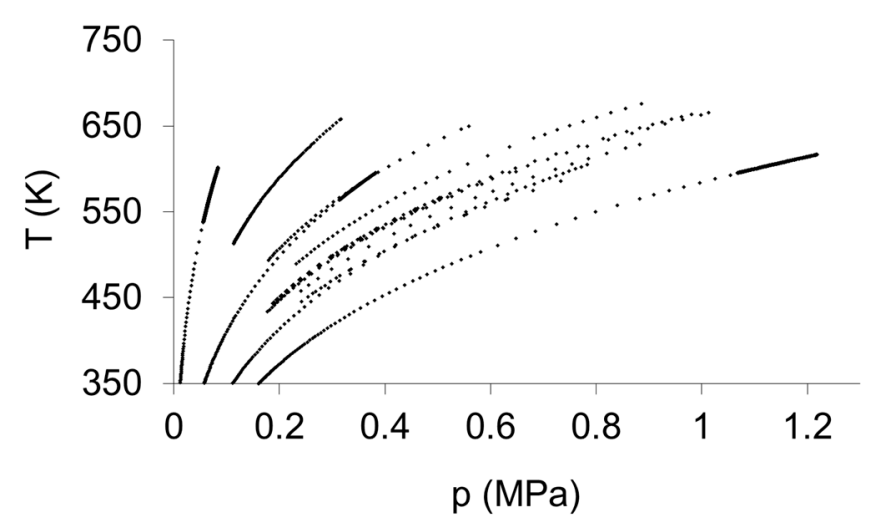

(a)

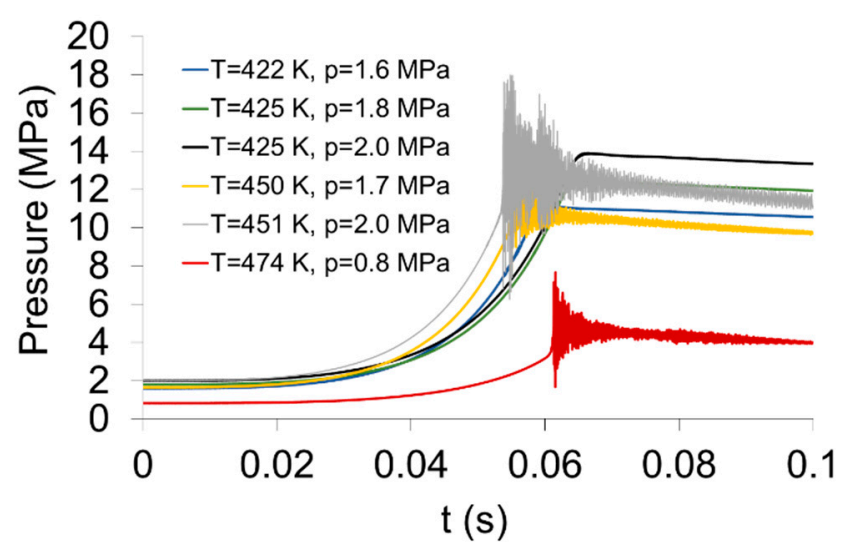

(b)

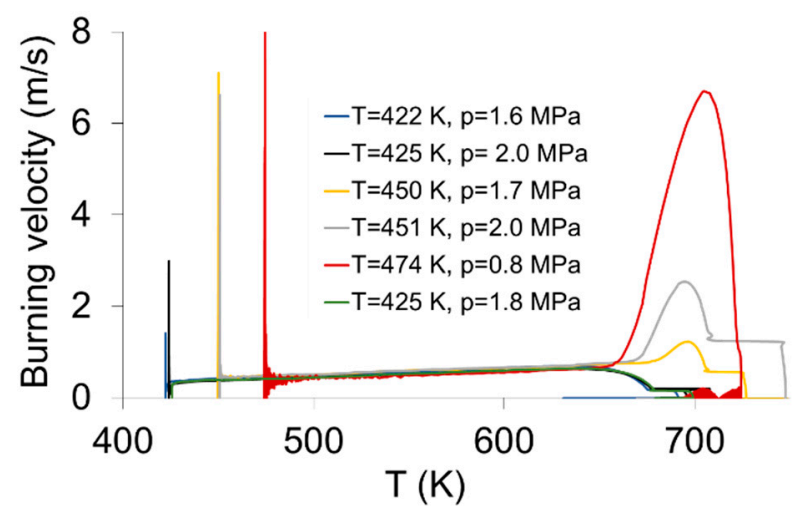

(c)

Figure 9. (a) Pressure-temperature diagram; (b) pressure; (c) burning velocity. Temperature-pressure map, the temporal evolution of pressure and burning velocity versus the unburned temperature for the combustions of n-heptane with a 0.9 of equivalence ratio.

\subsubsection{Results of n-Heptane for a 0.8 Fuel/Air Equivalence Ratio}

In the case of an equivalence ratio of 0.8 , the observed experimental behavior of the combustion process of $n$-heptane is qualitatively very similar to the 0.9 case. Autoignition appears in some 
combinations of initial high temperature and pressure, leading to very high apparent burning velocities in the latter part of the combustion process.

For brevity, only the final result is presented in the form of a burning velocity adjusted to a Metghalchi and Keck type correlation, Equation (6), where the value of the correlation coefficient $R^{2}$ is 0.984 and the standard error of estimation is $3 \%$.

$$
F r=0.8 \rightarrow C c\left(\frac{m}{s}\right)=0.27\left(\frac{T}{T_{0}}\right)^{2.77}\left(\frac{p}{p_{0}}\right)^{-0.33},
$$

To check the accuracy of the correlations proposed for n-heptane combustion (Equations (4)-(6)), they are compared with other authors' results. The values are compared with those obtained by Davis and Law (1998, [13]), Huang et al. (2004, [14]), Van Lipzig et al. (2011, [15]), Sileghem et al. (2013, [16]), Marshall et al. (2011, [12]), Kwon et al. (2000, [17]), Kumar et al. (2007, [18]), Chong et al. (2011, [19]) and Dirremberger et al. [20] in Figure 10, for ambient conditions of pressure and temperature. It is possible to see a good agreement between results of this work and the other authors' results.

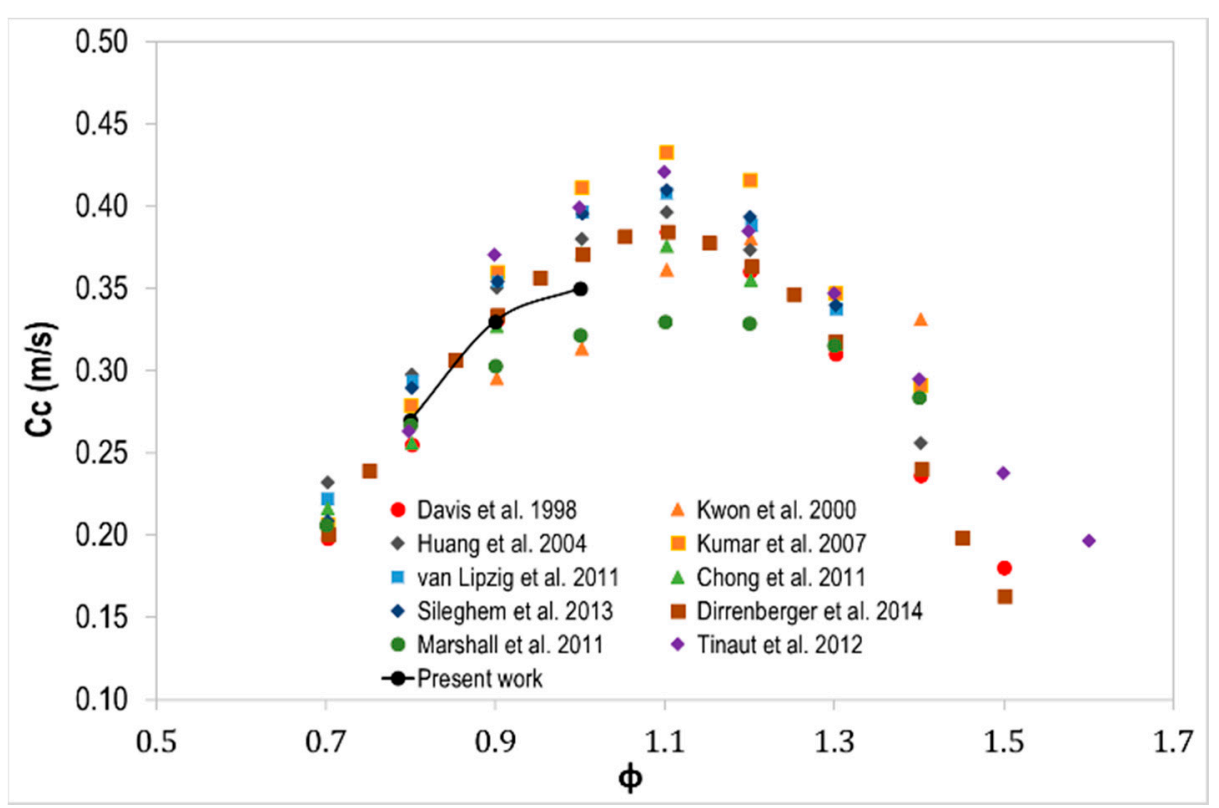

Figure 10. Comparison between the n-heptane burning velocities obtained in this work (black points) with the ones obtained by references [13].

\subsection{Burning Velocity of a 50\% n-Heptane and $50 \%$ Toluene Blend}

In this section, results for the burning velocity of a blend of 50\% n-heptane $/ 50 \%$ toluene, in mass, is obtained in the CVCB for different initial conditions of pressure, temperature and equivalence ratios of 0.8 and 1.0 (right). This mixture is considered a surrogate fuel, where the toluene represents the aromatic content. The validity range for the stoichiometric blend is an initial pressure between 0.1 and $0.9 \mathrm{MPa}$ and an initial temperature between 450 and $700 \mathrm{~K}$, and for the 0.8 equivalence ratio, an initial pressure ranging from 0.1 to $1.0 \mathrm{MPa}$ and an initial temperature from 360 to $700 \mathrm{~K}$.

Figure 11 shows the pressure-temperature map, temporal evolution of pressure and burning velocity versus the unburned temperature, for combustions of $50 \% \mathrm{n}$-heptane $/ 50 \%$ toluene for stoichiometric (left) and 0.8 (right) equivalence ratios. As in the case of pure n-heptane, for some initial conditions of pressure and temperature some oscillations can be observed in the pressure plots, associated to the onset of autoignition. In parallel, the apparent burning velocity increases suddenly and strongly after autoignition appears. There are more cases of autoignition apparition for the lean (0.8) mixture than for the stoichiometric mixture. This is a result of the trade-off between two competing processes: laminar combustion, which needs a time equivalent to the chamber radius over the burning 
velocity, and the autoignition process, with a delay time that depends on the pressure and temperature history of the air-fuel mixture experiments. Since the mixture is leaner when the laminar velocity is smaller, the time needed to complete the flame length is longer, thus making it bigger than the autoignition delay time and causing a generalized combustion of the remaining unburned mixture. This so-called abnormal combustion leads to a sharp increase in pressure, sometimes associated to secondary pressure waves that explain the oscillations in the pressure plots. When the two-zone thermodynamic model finds these sharp pressure increments, the apparent burning velocity computed as a result is very high, although not necessarily with a physical fundament.
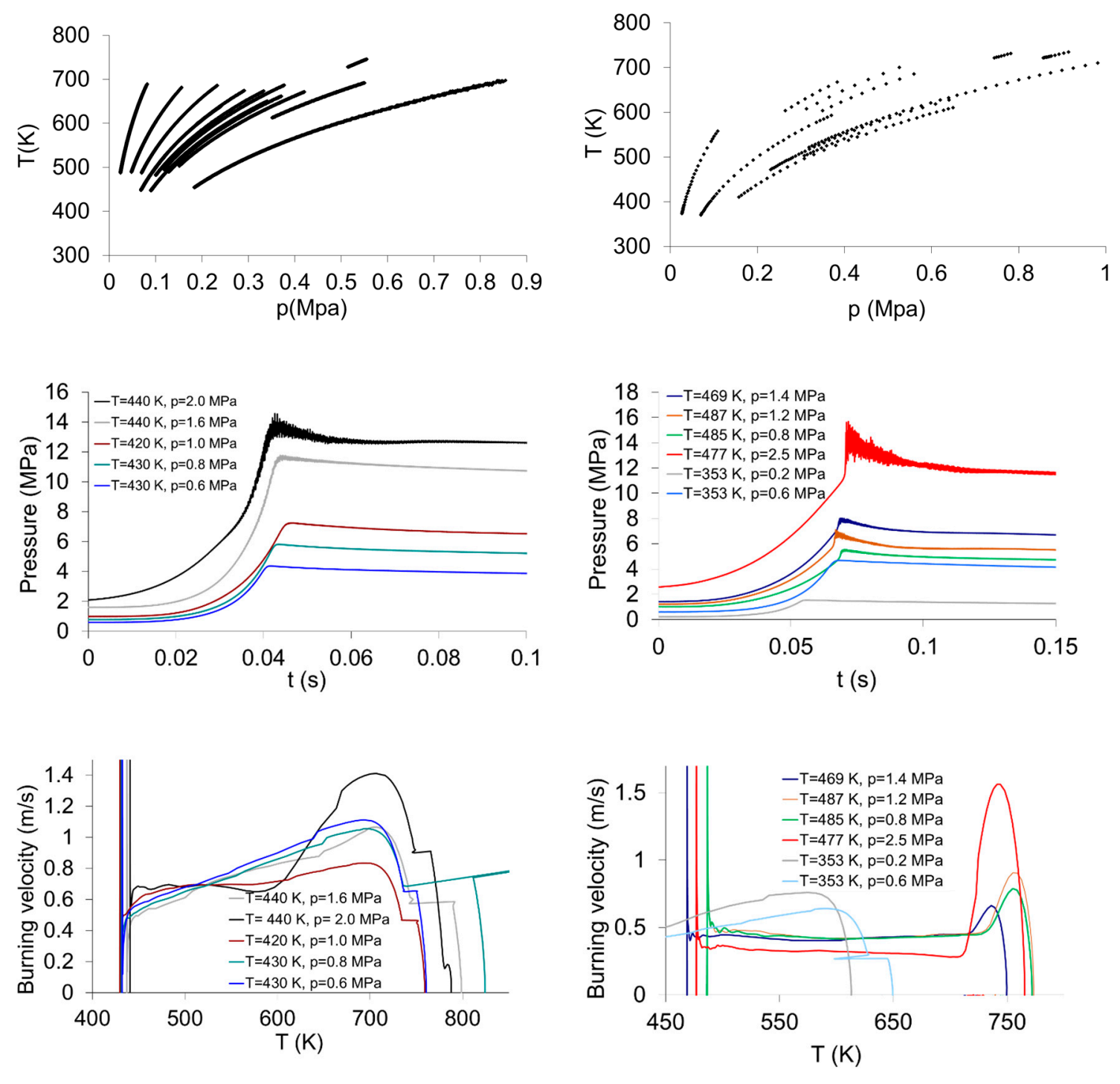

$$
\Phi=1
$$$$
\Phi=0.8
$$

Figure 11. A temperature-pressure map, the temporal evolution of pressure and burning velocity versus temperature, for the mixture of $50 \% \mathrm{n}$-heptane $/ 50 \%$ toluene, for different initial conditions and equivalence ratios (1.0-left, 0.8-right).

The burning velocities obtained with the two-zone thermodynamic model are adjusted to a correlation with the pressure and temperature shown in Equations (7) and (8) (for stoichiometric and 0.8 equivalence ratios, respectively). The value of the correlation coefficient $R^{2}$ is 0.950 and 0.976 and the standard error of estimation is $5 \%$ and $6 \%$, for the stoichiometric and 0.8 equivalence ratios. 


$$
\begin{aligned}
& F r=1 \rightarrow C c\left(\frac{m}{s}\right)=0.31\left(\frac{T}{T_{0}}\right)^{1.95}\left(\frac{p}{p_{o}}\right)^{-0.103} \\
& F r=0.8 \rightarrow C c\left(\frac{m}{s}\right)=0.33\left(\frac{T}{T_{0}}\right)^{2.19}\left(\frac{p}{p_{o}}\right)^{-0.24}
\end{aligned}
$$

\section{Conclusions}

A spherical constant volume combustion bomb has been used for the determination of the burning velocity of liquid fuels: iso-octane, $\mathrm{n}$-heptane and a mixture with toluene. A two-zone thermodynamic combustion model allows for the analysis of the pressure register during the combustion and to obtain some significant properties during the combustion process, allowing us to characterize the physical and thermochemical properties of the combustion, as can be done with the burning velocity, mass burned fraction, temperatures, etc.

The burning velocity of three liquid fuels: iso-octane, $\mathrm{n}$-heptane and a blend of $50 \% \mathrm{n}$-heptane $/ 50 \%$ toluene in mass, has been obtained for the elevated conditions of pressure and temperature (engine like conditions) and diverse equivalence ratios. The burning velocities of $n$-heptane and iso-octane have been compared with data obtained in the literature, for the same conditions, obtaining a good agreement with them. The burning velocities are expressed as power law correlations of pressure and temperature for a given fuel/air equivalence ratio. For the three fuels studied, the burning velocity enhances with temperature (with exponents of 1.91 in the case of iso-octane and 2.21 in the case of $\mathrm{n}$-heptane) during the combustion process. The dependence with pressure is the contrary-the burning velocity decreases with the increment of pressure (with exponents between 0.25 for iso-octane and 0.33 for $n$-heptane, with values between 0.10 and 0.23 for the $50 \%$ n-heptane $/ 50 \%$ toluene mixture).

The traces of pressure of iso-octane combustion are smooth, as well as the corresponding burning velocities. However, during the n-heptane combustion, some oscillations are detected in the pressure and burning velocity curves, especially for lean mixtures, which is due to the onset of autoignition processes. The blend of $\mathrm{n}$-heptane and toluene shows qualitatively the same behavior of $\mathrm{n}$-heptane, with strong increments in the apparent burning velocity curves once autoignition appears.

Author Contributions: Conceptualization, M.R. and F.V.T.; investigation, M.R. and A.C.; methodology, M.R.; supervision, F.V.T.; validation, M.R. and A.C.; writing—original draft, M.R.; writing—review and editing, M.R., F.V.T. All authors have read and agreed to the published version of the manuscript.

Funding: This research was funded by the Spanish government of science and innovation with the research project, PID2019-106957RB-C22.

Acknowledgments: This work was conducted by the Research group in Engines and Renewable Energies (MYER) from the University of Valladolid in Spain under the framework of the PID2019-106957RB-C22 research project.

Conflicts of Interest: The authors declare no conflict of interest.

\section{References}

1. Egolfopoulos, F.N.; Cho, P.; Law, C.K. Laminar flame speeds of methane-air mixtures under reduced and elevated pressures. Combust. Flame 1989, 76, 375-391. [CrossRef]

2. Konnov, A.A.; Mohammad, A.; Kishore, V.R.; Kim, N.I.; Prathap, C.; Kumar, S. A comprehensive review of measurements and data analysis of laminar burning velocities for various fuel+ air mixtures. Prog. Energy Combust. Sci. 2018, 68, 197-267. [CrossRef]

3. Bhavani Shankar, V.S.; Sajid, M.; Al-Qurashi, K.; Atef, N.; Alkhesho, I.; Ahmed, A.; Chung, S.; Roberts, W.; Morganti, K.; Sarathy, M. Primary Reference Fuels (PRFs) as Surrogates for Low Sensitivity Gasoline Fuels; SAE International: Warrendale, PA, USA, 2016.

4. Mueller, C.J.; Cannella, W.J.; Bruno, T.J.; Bunting, B.; Dettman, H.D.; Franz, J.A.; Huber, M.L.; Natarajan, M.; Pitz, W.J.; Ratcliff, M.A.; et al. Methodology for Formulating Diesel Surrogate Fuels with Accurate Compositional, Ignition-Quality, and Volatility Characteristics. Energy Fuels 2012, 26, 3284-3303. [CrossRef] 
5. Ra, Y.; Reitz, R.D. A reduced chemical kinetic model for IC engine combustion simulations with primary reference fuels. Combust. Flame 2008, 155, 713-738. [CrossRef]

6. Gülder, Ö.L. Laminar burning velocities of methanol, ethanol and isooctane-air mixtures. Symp. Int. Combust. 1982, 19, 275-281. [CrossRef]

7. Bradley, D.; Hicks, R.; Lawes, M.; Sheppard, C.; Woolley, R. The measurement of laminar burning velocities and Markstein numbers for iso-octane-air and iso-octane-n-heptane-air mixtures at elevated temperatures and pressures in an explosion bomb. Combust. Flame 1998, 115, 126-144. [CrossRef]

8. Metghalchi, M.; Keck, J.C. Burning velocities of mixtures of air with methanol, isooctane, and indolene at high pressure and temperature. Combust. Flame 1982, 48, 191-210. [CrossRef]

9. Galmiche, B.; Halter, F.; Foucher, F. Effects of high pressure, high temperature and dilution on laminar burning velocities and Markstein lengths of iso-octane/air mixtures. Combust. Flame 2012, 159, 3286-3299. [CrossRef]

10. Müller, U.; Bollig, M.; Peters, N. Approximations for burning velocities and Markstein numbers for lean hydrocarbon and methanol flames. Combust. Flame 1997, 108, 349-356. [CrossRef]

11. Varea, E.; Modica, V.; Renou, B.; Boukhalfa, A.M. Pressure effects on laminar burning velocities and Markstein lengths for Isooctane-Ethanol-Air mixtures. Proc. Combust. Inst. 2013, 34, 735-744. [CrossRef]

12. Marshall, S.P.; Taylor, S.; Stone, C.R.; Davies, T.J.; Cracknell, R.F. Laminar burning velocity measurements of liquid fuels at elevated pressures and temperatures with combustion residuals. Combust. Flame 2011, 158, 1920-1932. [CrossRef]

13. Davis, S.; Law, C. Determination of and fuel structure effects on laminar flame speeds of C1 to C8 hydrocarbons. Combust. Sci. Technol. 1998, 140, 427-449. [CrossRef]

14. Huang, Y.; Sung, C.; Eng, J. Laminar flame speeds of primary reference fuels and reformer gas mixtures. Combust. Flame 2004, 139, 239-251. [CrossRef]

15. Van Lipzig, J.; Nilsson, E.; De Goey, L.; Konnov, A.A. Laminar burning velocities of n-heptane, iso-octane, ethanol and their binary and tertiary mixtures. Fuel 2011, 90, 2773-2781. [CrossRef]

16. Sileghem, L.; Alekseev, V.A.; Vancoillie, J.; Van Geem, K.M.; Nilsson, E.J.K.; Verhelst, S.; Konnov, A.A. Laminar burning velocity of gasoline and the gasoline surrogate components iso-octane, n-heptane and toluene. Fuel 2013, 112, 355-365. [CrossRef]

17. Kwon, O.; Hassan, M.; Faeth, G. Flame/stretch interactions of premixed fuel-vapor/O/N flames. J. Propuls. Power 2000, 16, 513-522. [CrossRef]

18. Kumar, K.; Freeh, J.; Sung, C.; Huang, Y. Laminar flame speeds of preheated iso-octane/O2/N2 and n-heptane/O2/N2 mixtures. J. Propuls. Power 2007, 23, 428-436. [CrossRef]

19. Chong, C.T.; Hochgreb, S. Measurements of laminar flame speeds of liquid fuels: Jet-A1, diesel, palm methyl esters and blends using particle imaging velocimetry (PIV). Proc. Combust. Inst. 2011, 33, 979-986. [CrossRef]

20. Dirrenberger, P.; Glaude, P.-A.; Bounaceur, R.; Le Gall, H.; Da Cruz, A.P.; Konnov, A.; Battin-Leclerc, F. Laminar burning velocity of gasolines with addition of ethanol. Fuel 2014, 115, 162-169. [CrossRef]

21. Tinaut, F.V.; Reyes, M.; Giménez, B.; Pastor, J.V. Measurements of $\mathrm{OH}^{*}$ and $\mathrm{CH}^{*}$ Chemiluminescence in Premixed Flames in a Constant Volume Combustion Bomb under Autoignition Conditions. Energy Fuels 2011, 25, 119-129. [CrossRef]

22. Tinaut, F.V.; Melgar, A.; Giménez, B.; Reyes, M. Characterization of the combustion of biomass producer gas in a constant volume combustion bomb. Fuel 2010, 89, 724-731. [CrossRef]

23. Tinaut Fluixá, F.; Giménez Olavarría, B.; Iglesias Hoyos, D.; Lawes, M. Experimental Determination of the Burning Velocity of Mixtures of n-Heptane and Toluene in Engine-like Conditions. FlowTurbul. Combust. 2012, 89, 183-213. [CrossRef]

24. Horrillo, A. Utilization of Multi-Zone Models for the Prediction of the Pollutant Emissions in the Exhaust Process in Spark Ignition Engines; University of Valladolid: Valladolid, Spain, 1998.

25. Heywood, J.B. Internal Combustion Engine Fundamentals; Hill, M., Ed.; McGraw-Hill: New York, NY, USA, 1988.

26. Reyes, M.; Tinaut, F.V.; Horrillo, A.; Lafuente, A. Experimental characterization of burning velocities of premixed methane-air and hydrogen-air mixtures in a constant volume combustion bomb at moderate pressure and temperature. Appl. Therm. Eng. 2018, 130, 684-697. [CrossRef]

(C) 2020 by the authors. Licensee MDPI, Basel, Switzerland. This article is an open access article distributed under the terms and conditions of the Creative Commons Attribution (CC BY) license (http://creativecommons.org/licenses/by/4.0/). 